5. Самаев И.Р., Бирюков О.И. Влияние пробиотического препарата «Био Плюс 2Б» на развитие и резистентность баранчиков // Овцы, козы, шерстяное дело. - 2015. - № 3. - С. 26-27.

6. Самаев И.Р., Бирюков О.И. Применение пробиотических препаратов при выращивании баранчиков цигайской породы // Научная жизнь. - 2016. - № 4. С. $154-163$.

7. Самаев И.Р., Бирюков О.И. Продуктивность молодняка овец при использовании пробиотических препаратов «Био Плюс 2Б» и «Олин» баранчиков / / Овцы, козы, шерстяное дело. - 2017. - № 2. - С. 34-36
Самаева Ксения Алексеевна, аспирант кафедры «Технология производства и переработки продукции животноводства», Саратовский государственный аграрный университет имени Н.И. Вавилова. Россия.

Бирюков Олег Игрисович, канд. с.-х. наук, доцент кафедры «Технология производства и переработки продукции животноводства», Саратовский государственный аграрный университет имени Н.И. Вавилова. Россия.

4100о5, г. Саратов, ул. Соколовая, 335.

Тел.: (8452) 69-25-32; e-mail: birykovoi@yandex.ru.

Ключевые слова: ягнята; живая масса; пробиотики; пребиотики; мясная продуктивность.

\title{
INFLUENCE OF THE PROBIOTIC PREPARATION “BIO PLUS YC” AND PREBIOTIC PREPARATION “KORMOMIX MOS”ON THE DEVELOPMENT AND MEAT PRODUCTIVITY OF STAVROPOL RAMS
}

Samaeva Ksenia Alekseevna, Post-graduate Student of the chair "Technology of Production and Processing of Livestock Products", Saratov State Agrarian University named after N.I. Vavilov. Russia.

Biryukov Oleg Igrisovich, Candidate of Agricultural Sciences, Associate Professor of the chair "Technology of Production and Processing of Livestock Products", Saratov State Agrarian University named after N.I. Vavilov. Russia.
Key words: lambs; live weight; probiotics; prebiotics; meat production.

The results of using the probiotic preparation "BioPlus $Y C$ " and the prebiotic preparation "Kormomiks MOS" for growing ram's Stavropol breed up to 8 months of age are presented. Their positive influence on the growth of live weight and meat production has been established.

\section{ВЗАИМОДЕЙСТВИЕ КУЛЬТУРНЫХ РАСТЕНИЙ И ВРЕДНЫХ ОБЪЕКТОВ В АГРОФИТОЦЕНОЗАХ}

\author{
СПИРИдОНОВ Юрий Яковлевич, Всероссийский научно-исследовательский институт \\ фитопатологии
}

БУдЫНков Николай Иванович, Всероссийский научно-исследовательский институт фитопатологии

дУдкин Игорь Витальевич, Курский научно-исследовательский институт агропромышленного производства

СТРИжкОВ Николай Иванович, ФГБНУ«НИИСХ Юго-Востока»

СУМИНОВА Наталья Борисовна, Саратовский государственный аграрный университет имени Н.И. Вавилова

\section{НИКОЛАЙЧЕНКО Наталия Викторовна, Саратовский государственный аграрный} университет имени Н.И. Вавилова

ДАУЛЕТОВ МахатАскарбекович, Саратовский государственный аграрный университет имени Н.И. Вавилова

ЛЕНОВИЧ Дарья Рудольфовна, Саратовский государственный аграрный университет имени Н.И. Вавилова

Изучено взаимодействие культурных и сорных растений и вредителей в агрофитоценозе. Определены пороги вредоносности для обоснования раџионального использования средств защиты растений. Установлены экономические пороги вредоносности вредных организмов, что служит научной основой для разработки эффективных мер боръбъ с ними.

Введение. Современное сельское хозяйство невозможно представить без эффективного и рационального использования химических средств защиты растений (гербицидов, фунгицидов, инсектицидов) $[10-12,15,16]$. Один из основных факторов, отрицательно влияющих на продуктивность сельскохозяйственных культур, - сор- ные растения. В Поволжье ежегодные потери изза сорняков достигают на зерновых культурах $30 \%$, на технических - $50 \%$, а в отдельные годы $90 \%[1,5,6,8]$.

Кроме того, серьезную угрозу урожайности полевых культур и их качеству представляет комплекс вредителей $[2-4,7,9,13,14]$. Для научного 
обоснования эффективности мер защиты растений от вредных объектов необходимо изучить взаимодействие культурных и сорных растений, вредителей в агрофитоценозе и определить пороги вредоносности сорняков, вредителей на посевах возделываемых культур. Для решения этой задачи были проведены специальные опыты, результаты которых стали научной основой для разработки эффективных мер борьбы с сорной растительностью и вредителями.

Цель исследований - установить экономические пороги вредоносности (ЭПВ) и экономические пороги целесообразности (ЭПЦ) применения гербицидов и инсектицидов.

Методика исследований. Исследования проводили в условиях опытных стационаров, лабораторий агроландшафтов и защиты растений ФГБНУ «НИИСХ Юго-Востока» в 2006-2017 гг. Погодные условия в период исследований в полной мере охватывали всю совокупность климатических особенностей региона, отличаясь разнообразием.

Изучение почвенной фауны и фауны растительного яруса проводили на склоновых агроландшафтах. Почвы - чернозем южный маломощный тяжелосуглинистый. Почва участка характеризовалась сравнительно небольшой мощностью гумусового горизонта - 40-45 см. Объемная масса

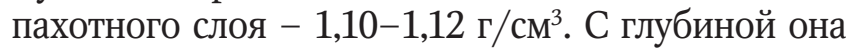
возрастала до 1,73 г $/ \mathrm{cm}^{3}$, а в материнской породе вновь снижалась до 1,59 г/ $\mathrm{cm}^{3}$.

Максимальная гигроскопичность и влажность завядания в пахотном слое южных черноземов составляет соответственно 9,5-10,6 и 14,315,9 \%. Запасы доступной влаги в метровом слое, соответствующие предельной полевой влагоемкости, равняются 188-194 мм. Порозность - 54$57 \%$, скорость впитывания воды - 0,09$0,13 \mathrm{~cm} / \mathrm{c}$.

Содержание гумуса в пахотном слое составляет 4,49-4,56 \% с глубиной оно равномерно снижается до 2,10-1,94 \%. Содержание азота в пахотном слое - 0,238 \%. Запасы валового фосфора мало изменяются по профилю и колеблются от 0,102 до 0,127 \%. Сумма поглощенных оснований в горизонте A - 39,9-40,0 мг/экв. на 100 г. почвы. В составе поглощенных оснований преобладает кальций. Степень насыщенности основаниями 93-96\%.

В ходе проведения исследований выполняли почвенные раскопки (пробы $0,25 \mathrm{M}^{2}$ с размером $0,5 \times 0,5$ м) на контрольных вариантах опыта с послойной ручной разборкой проб (0-20 и 2040 см) и просеиванием почвы на глубину пахотного слоя и идентификацией фитофагов. Учеты выполняли в ранневесенний период при наступлении готовности почвы.

Также проводили исследования по определению запаса семян сорных растений. Образцы почвы брали буром, через каждые 10 см на глубину 30 см (пахотного слоя) по методике НИИСХ ЮгоВостока. Взятые пробы отмывали в капроновых мешочках. После высушивания их разбирали по отдельным видам и пересчитывали на 1 м². Наземную засоренность учитывали количественным методом с наложением рамки 0,25 м $^{2}$ в 100 точках и пересчитывали на $1 \mathrm{~m}^{2}$.

Пороги вредоносности сорняков изучали по методике Б.М. Смирнова (1969). С каждого участка поля чистого и засоренного (по $0,25 \mathrm{~m}^{2}$ ) отбирали по 30 снопов, в них подсчитывали количество растений культуры и сорняка, определяли общую растительную массу и отдельно массу культуры и соответствующего сорняка, урожай зерна, вынос NPK всеми видами изучаемых растений.

Оценку численности фитофагов проводили по стационарной методике путем учета на пробных площадках размером $0,25 \mathrm{~m}^{2}(0,5 \times 0,5 \mathrm{~m})$ с числом проб 200 шт. на контрольных стадиях вредителя. Вредоносность определяли по стандартной методике.

Результаты исследований. Появление сорной растительности в посевах сельскохозяйственных культур и в парах еще не свидетельствует о безусловной необходимости ее полного и немедленного уничтожения. Взаимосвязи культурных растений и сорняков между собой и окружающей средой могут быть отражены статистическими закономерностями. Знание этих закономерностей можно успешно использовать в разработке мер борьбы с сорными растениями.

При слабой засоренности посевов вред от сорняков абсолютно неощутим. С увеличением массы и численности сорняков в посевах вредоносность их неуклонно возрастает, что сопровождается снижением урожайности сельскохозяйственных культур. Количественная оценка зависимости урожая от сорных растений позволит решить не только тактические вопросы уничтожения сорняков, но и определить стратегию борьбы с сорной растительностью на основе прогноза динамики этой зависимости.

Следует различать общую и удельную вредоносность сорняков. Удельная вредоносность сорной растительности - это величина потерь урожая сельскохозяйственных культур в расчете на единицу обилия сорняков (на 1 г, на 1 растение). Чем выше засоренность посевов, тем меньше удельная вредоносность сорняков. При одинаковом числе уничтоженных сорняков прибавка урожая культуры на сильно засоренном участке значительно меньше, чем на слабозасоренном. На полях с низкой урожайностью экономический порог вредоносности сорняков определяется прибавкой урожая на 8-12 \%. Для ряда технических культур истребительные мероприятия окупаются прибавкой урожая уже в $2-4 \%$.

Производственная деятельность любого сельскохозяйственного предприятия оправдана при условии, что оно получает экономическую прибыль. Минимальная экономическая прибыль достигается, если рентабельность производства составляет не менее 50 \%. Порог экономической целесообразности борьбы с сорняками- это такое их обилие, полное уничтожение которых обеспечивает 
рентабельность системы не менее 50 \%. Экономические пороги вредоносности сорняков зависят от почвенно-климатических условий и экономических факторов. Поэтому целесообразно разрабатывать зональные пороги и конкретизировать их применительно к хозяйственным условиям.

Экономические пороги вредоносности сорняков и целесообразности применения гербицидов обычно отражают уровень засоренности на конкретную дату или фазу культурных растений и меняются в зависимости от сроков проведения учета. Так, на посевах озимой пшеницы при осенних учетах засоренности по степени проективного покрытия экономический порог вредоносности равен в среднем $3 \%$, порог целесообразности применения гербицидов - $5 \%$. Весной в конце фазы кущения эти показатели составляют соответственно 5 и 10 \%. В практических целях следует учитывать экономический порог в начале проведения обработок гербицидами. Так как применение гербицидов приводит к сокращению затрат на прополки, уход за посевами, уборку урожая, то при расчете экономических порогов вредоносности следует учитывать и эти величины. Величина сокращения трудовых затрат на применение гербицидов определяется делением показателей затрат на сменную тарифную ставку рабочего, проводящего прополку.

Результаты наших опытов показали, что при засорении многолетними сорняками яровой пшеницы экономический порог вредоносности отмечен

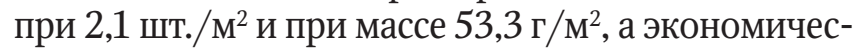
кий порог целесообразности применения герби-

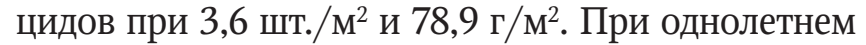
двудольном типе засоренности экономический порог вредоносности составляет 4,2 шт./ $\mathrm{M}^{2}$ при их массе 32,0 г, а экономически целесообразно с ними

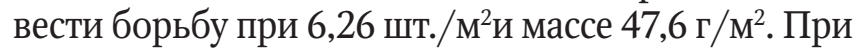
злаковом типе засоренности защитные мероприятия необходимы, если она составляет больше 19,05 шт./м² и 63,2 г, а экономический порог целесообразности применения гербицидов при 30,12 шт./ $\mathrm{M}^{2}$ и массе 105,3 г. Для всех сорняков эти показатели составляют 6,68 шт./ $\mathrm{M}^{2}$ при массе

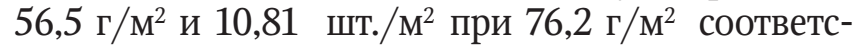
твенно (см. таблицу).

При засоренности нута корнеотпрысковыми сорняками экономический порог вредоносности наступает при 2,66 шт. и массе 20,8 г/ $\mathrm{M}^{2}$, а экономический порог целесообразности борьбы с ними при 4,14 шт. и массе 33,7 г/м². При засорении нута двудольными однолетними сорняками экономический порог отмечен при 1,94 шт./м² (74,9 г), а порог целесообразности борьбы с ними 3,00 шт./м²(115,9 г). ЭПВ злаковых однолетних

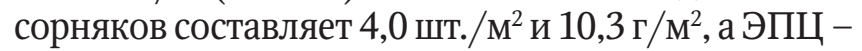
6,19 шт. $/ \mathrm{M}^{2}$ и $16,0 \Gamma / \mathrm{M}^{2}$, а всех сорняков соот-

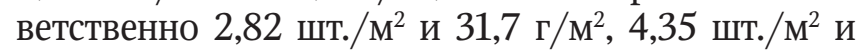
$49,1 \Gamma / \mathrm{M}^{2}$.

Для посевов проса определен экономический порог вредоносности многолетних сорняков

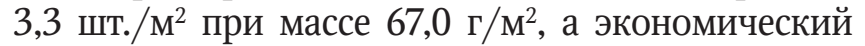

порог целесообразности применения гербицидов против этих сорняков составил 5,0 шт./ $\mathrm{M}^{2}$ при мас-

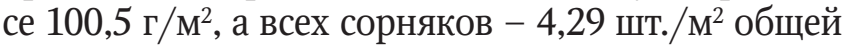
массой 67,0 г $/ \mathrm{M}^{2}$.

Для овса ЭПВ составляет 2,3 шт./ $\mathrm{M}^{2}\left(58,6\right.$ г $\left./ \mathrm{M}^{2}\right)$ многолетних сорняков, а ЭПЦ использования гербицидов - при 4 шт. $/ \mathrm{M}^{2}\left(87,8\right.$ г $\left./ \mathrm{M}^{2}\right)$. При однолетнем двудольном типе засоренности ЭПВ отмечает-

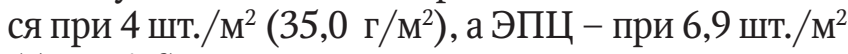
$\left(52,4\right.$ г $\left./ \mathrm{M}^{2}\right)$.

Аридизация климата и связанная с ним перестройка агроклиматических характеристик возделывания полевых культур требует корректировки стратегии и тактики интегрированной защиты посевов для предотвращения негативного влияния стрессовых нагрузок. В Поволжье, которое характеризуется атмосферной засухой, сопровождающейся, как правило, дефицитом влаги в почве, снижается устойчивость растений к повреждениям, ослабляются компенсаторные реакции. В то же время высокие температуры и сухость воздуха повышают активность вредителей, особенно ксерофилов, вредоносность которых существенного возрастает.

Так, в ходе многолетнего миграционного поведения перезимовавших хлебных клопов выявлена устойчивая тенденция смещения сроков завершения миграции клопов на посевы на более ранний период. Ранние сроки появления клопов на посевах, так же как и ранние сроки завершения миграции, с началом интенсивного питания вредителя в условиях региона отмечаются в годы ранневесенних засух. В условиях Поволжья наиболее критическими фазами роста и развития яровых культур в фитосанитарном отношении являются всходы и начало кущения. В этот период кроме хлебных клопов главными вредителями являются фитофаги, изреживающие всходы и снижающие продуктивность посевов. Из этой группы особой вредоносностью характеризуются виды, обладающие выраженной термофильностью (листовые и стеблевые блошки) и гидротаксисом (проволочники). По этим причинам пороги вредоносности для данных вредителей снижаются. Для листовых блошек порог вредоносности - 300 экз. при энтомологическом кошении (50 двойных взмахов сачка) или $20-25$ экз. $/ \mathrm{M}^{2}$. Для проволочников уровень ЭПВ в условиях засухи - 3-5 экз./ $\mathrm{M}^{2}$.

Особо агрессивными вредителями зерновых культур в период кущения кроме вредной черепашки и остроголовых клопов являются скрытностеблевые фитофаги, листоед пьявица. Высокая миграционная активность этих насекомых, большой коэффициент размножения и приспособленность к засушливому степному климату ставят их в разряд хронических массовых фитофагов.

В условиях засухи экономические пороги вредоносности имеют минимальные значения уровней численности вредных объектов, указанных в регламентах по использованию химических средств борьбы. Для перезимовавшего клопа 
вредной черепашки в засушливых условиях экономический порог вредоносности составляет 1,5 экз. $/ \mathrm{M}^{2}$ на озимой пшенице и 0,3 экз. $/ \mathrm{M}^{2}$ на яровой. Для злаковых тлей ЭПВ - 3 экз./колос при заселенности более 60 \% на яровой пшенице и 5 экз./колос при заселенности более 60 \% на озимой пшенице. Для листоеда пьявицы ЭПВ на посевах яровой пшеницы и ячменя - 8-10 экз./ $\mathrm{M}^{2}$, для озимой пшеницы - более 30 экз./м².

Для имаго хлебных жуков, появляющихся на посевах в фазу колошения - цветения, характерна неравномерность распределения на посевах. В засушливых условиях значительная часть вредителей сосредоточена на краевых полосах, где зерно дольше находится в пластическом состоянии. В этом случае при использовании активных приемов защиты можно ограничиться локальными обработками (ЭПВ для имаго жуков - 4 экз. $/ \mathrm{M}^{2}$ ).

Заключение. Исследование взаимодействия между культурными растениями и вредными объектами и полученные их количественные характеристики имеют как теоретическое, так и практическое значение и позволяют объективно оценить характер межвидовой борьбы, выявить виды наиболее опасные для культурных растений.

Установление порогов вредоносности сорной растительности и вредителей в посевах сельскохозяйственных культур в Поволжье позволяет научно обосновать меры борьбы с ними, установить целесообразность использования химических средств защиты растений в современных технологиях.

\section{СПИСОК ЛИТЕРАТУРЫ}

1. Агроэкологические аспекты применения химических средств защиты посевов проса от сорных растений в Саратовском Правобережье / М.А. Даулетов [и др.] // Аграрный научный журнал. - 2017. - № 9. C. 3-9.

2. Агрофизические свойства черноземов Кубани и урожайность озимой пшеницы в зависимости от технологии возделывания / В.М. Кильдюшкин [и др.] // Аграрный научный журнал. - 2017. - № 7. C. 25-28.

3. Влияние химических средств защиты на обменные процессы в растениях, их химический состав, прохождение фенофаз / В.Б. Лебедев [и др.] // Вестник Саратовского госагроуниверситета им. Н.И. Вавилова. - 2007. - № 5. - С. 18-20.

4. В расчете на комбинированный тип засоренности / В.Б. Лебедев [и др.] // Защита и карантин растений. - 2004. - № 2. - С. 41-42.

5. Дудкин И.В., Дудкин В.М., Айдиев А.Я. Экологические аспекты формирования систем земледелия и защиты растений // Вестник Курской государственной сельскохозяйственной академии. - 2017. - № 7. C. 2-7.

6. Интегрированная технология защиты посевов полевых культур от болезней, вредителей и сорняков на основе биологических и химических методов / Н.И. Стрижков [и др.]. - Саратов, 2017. - 56 с.

7. Каменченко С.Е., Стрижков Н.И., Наумова Т.В.




Факторы, влияющие на динамику популяций вредных саранчовых в Нижнем Поволжье // Земледелие. - 2012. - № 1. - С. 41-43.

8. Каменченко С.Е., Стрижков Н.И., Наумова Т.В. Эколого-биоценотические закономерности размножения лугового мотылька в агроценозах Нижнего Поволжья // Земледелие. - 2013. - № 3. - С. 37-39.

9. Каменченко С.Е., Стрижков Н.И., Наумова Т.В. Вредоносность остроголовых клопов на зерновых культурах в Поволжье // Земледелие. - 2015. - № 2. C. 37-38.

10. Продуктивность расторопши пятнистой в зависимости от способов обработки почвы и химических средств защиты в сухой степи Поволжья / M.Н. Худенко [и др.] // Аграрный научный журнал. - 2016. № 12. - С. $43-49$.

11. Применение препарата Гермес при возделывании подсолнечника / Ю.Я. Спиридонов [и др.] // АПК России. - 2017. - Т. 24. - № 2. - С. 303-307.

12. Разработка технологии борьбы с вредными организмами с помощью Секатора турбо, Ламадора, Фалькона и других препаратов в посевах яровой пшеницы / Ю.Я. Спиридонов [и др.] // АПК России. - 2017. - Т. 2. - № 3. - С. 636-642.

13. Разработка интегрированной технологии защиты посевов полевых культур от болезней, вредителей и сорняков на основе биологических и химических методов / Ю.Я. Спиридонов [и др.] / / Аграрный научный журнал. - 2017. - № 9. С. $37-42$.

14. Технология возделывания яровой твердой пшеницы с применением препаратов Секатор турбо, Баритон, Фалькон, Нагро и других / Ю.Я. Спиридонов [и др.] // Аграрный научный журнал. - 2017. - № 3. - С. 30-36.

15. Nikolaichenko N.V., Eskov I.D., Muraveva M.V., Strizhkov N.I., Azizov Z.M. Productivity and plant protection from diseases and pests of milk thistle (variety amulet) in chernozems in the steppe zone of the Volga region // Journal of Pharmaceutical Sciences and Research, 2017,No. 7, P. 1164-1168.

16. Nikolaychenko N.V., EskovI.D.,Druzhkin A.F., Kishnikatina A.N., Strizhkov N.I., Shyurova N.A. Yield, oil content and biochemical composition of seeds of milk thistle, depending on the methods of soil cultivation in the Volga region steppe zone // Journal of Pharmaceutical Sciences and Research, 2018, No. 10 (1), P. 223-227.

Спиридонов Юрий Яковлевич, $\partial-p$ биол. наук, проф., зав. отделом гербологии, Всероссийский научно-исследовательский институт фитопатологии. Россия.

Будынков Николай Иванович, канд. биол. наук, ведущий научный сотрудник лаборатории экологии микроорганизмов, Всероссийский научно-исследовательский институт фитопатологии. Россия.

143050, Московская обл., Одинцовский p-н, p.n. Большие Вяземы, ул. Институт, владение 5.

Тел.: (495) 597-42-28.

Дудкин Игорь Витальевич, ведущий научный сотрудник отдела растениеводства, Курский научно-исследовательский институт агропромышленного производства. Россия.

305526, Курская обл., Курский р-н, пос. Черёмушки, 108.

Тел.: (4712) 59-54-85; e-mail: kniiapp@mail.ru.

Стрижков Николай Иванович, $\partial-p$ c.-х. наук, гл. научный сотрудник лаборатории защиты растений, ФГБНУ «НИИСХ Юго-Востока». Россия.

410010, г. Саратов, ул. Тулайкова, 7.

Тел.: (8452) 64-74-39; e-mail: raiser-saratov@mail.ru.

Суминова Наталья Борисовна, канд. с.-х. наук, доцент кафедры «Защита растений и плодоовощеводство», Саратовский государственный аграрный университет имени Н.И. Вавилова. Россия.

Николайченко Наталия Викторовна, $\partial-p$ c.- $x$. наук, проф. кафедры «Защита растений и плодоовощеводство», Саратовский государственный аграрный университет имени Н.И. Вавилова. Россия.

Даулетов Махат Аскарбекович, канд. с.-х. наук, старший преподаватель кафедры «Ботаника, химия и экология», Саратовский государственный аграрный университет имени Н.И. Вавилова. Россия.

Ленович Дарья Рудольфовна, аспирант кафедры «Защита растений и плодоовощеводство», Саратовский государственный аграрный университет имени Н.И. Вавилова. Россия.

410012, г. Саратов, Театральная пл., 1.

Тел.: (8452) 64-79-50.

Ключевые слова: удельная вредоносность; сорные растения; вредители; потери урожая; культуры.

\section{INTERACTION OF CULTURAL PLANTS AND HARMFUL OBJECTS IN AGROPHYTOCENOSIS}

Spiridonov Yuriy Yakovlevich, Doctor of Biological Sciences, Academician, Professor, Head of the department of herbology, All-Russian Scientific Research Institute for Experimental Physics. Russia.

Budynkov Nikolay Ivanovich, Candidate of Biological Sciences, Leading Researcher of the laboratory of microorganism ecology, All-Russian Scientific Research Institute for Experimental Physics. Russia.

Dudkin Igor Vitalyevich, Leading Researcher of the laboratory of microorganism ecology, All-Russian Scientific Research Institute for Experimental Physics. Russia.

Strizhkov Nikolay Ivanovich, Doctor of Agricultural Sciences, Senior Researcher of the laboratory of plant protection, Agricultural State Research Institute for South-East Region. Russia.

Suminova Natalya Borisovna, Candidate of Agricultural Sciences, Associate Professor of the chair "Plant Protection and Horticulture”, Saratov State Agrarian University named after N.I. Vavilov. Russia.

Nikolaychenko Natalya Viktorovna, Doctor of Agricultural Sciences, Professor of the chair "Plant Protection and Hor- ticulture", Saratov State Agrarian University named after N.I. Vavilov. Russia.

Dauletov Makhat Askarbekovich, Candidate of Agricultural Sciences, Senior Teacher of the chair "Botany, Chemistry and Ecology", Saratov State Agrarian University named after N.I. Vavilov. Russia.

Lenovich Darya Rudolphovna, Post-graduate Student of the chair "Botany, Chemistry and Ecology", Saratov State Agrarian University named after N.I. Vavilov. Russia. culture.

Key words: specific weediness; weed plants; pests; loss of crop;

The interaction of cultural and weed plants and pests in agrophytocenosis is studied. The thresholds of harmfulness are determined to justify the rational use of plant protection products. Economic thresholds of pests' harmfulness are established. This serves as the scientific basis for developing effective pets' management. 